\title{
Evidence of Fungicides Degradation by Rhizobia
}

\author{
Hassan Moawad1, Wafaa M. Abd El-Rahim1* ${ }^{*}$, Haitham Shawky², Aziz M. Higazy³, \\ Zakaria Y. Daw ${ }^{3}$ \\ ${ }^{1}$ Department of Agricultural Microbiology at National Research Center, Cairo, Egypt \\ ${ }^{2}$ Department of Agricultural Microbiology at faculty of Agriculture, Cairo University, Cairo, Egypt \\ ${ }^{3}$ Collage of Applications Science, MISR University for Science and Technology, 6th of October City, Egypt \\ Email: wafaa10m@hotmail.com
}

Received 2 April 2014; revised 26 May 2014; accepted 13 June 2014

Copyright (C) 2014 by authors and Scientific Research Publishing Inc.

This work is licensed under the Creative Commons Attribution International License (CC BY).

http://creativecommons.org/licenses/by/4.0/

(c) (i) Open Access

\section{Abstract}

Fungicides which are not easily degradable have the greatest adverse effects on soil microbes. These pesticides negatively affect the growth and multiplication of fungi and bacteria and consequently cause the disturbance of the natural soil microbial balance. In this study two fungicide tolerant isolates of rhizobia; clover isolate (TA1) and peanut isolate (8) were assessed in their capacity to degrade Vitavax and Rizolex. The performance of these isolates in fungicides degradation was tested using the colorimetric assay for Rizolex and the HPLC analysis for Vitavax to detect the degradation products. Using HPLC analyses, the control sample showed specific peak indicating the Vitavax presence in the medium. The specific peak did not change in the control samples throughout the experiment.With the strainTA1 the specific peak of the Vitavax fungicides started to reduce as the incubation time goes on. The Vitavax fungicide did not degrade completely after 240 hours of incubation with rhizobial isolate. The Rizolex used in this study contained blend of Thiram (active ingredient of Rizolex) and Tolcofs methyl fungicides in 1:1 ratio. The biodegradation of Rizolex in the liquid media showed the formation of two new intermediates which were released into the medium indicating the degradation of the tested fungicide by peanut rhizobial isolate No. 8 in 48 hrs of incubation $45 \%$ of this compound was degraded. This work shows that the selection of fungicides tolerant rhizobial strains is important to protect the rhizobial inoculants from the toxic effect of the pesticides.

\section{Keywords}

Fungicides, Rhizobia, Biodegradation, HPLC Analyses

\footnotetext{
*Corresponding author.
} 


\section{Introduction}

Microbial degradation is an important step in the disappearance and, in most cases detoxification of pesticides. Many soil applied pesticides are degraded more rapidly following repeated application at the same site [1] [2]. It is well known that fungicides which are not easily degradable have the greatest adverse effects on soil microbes and consequently cause the disturbance of the natural microbial balance [3] [4]. Pesticides applied to soil, plant foliage or directly on seed can reach the soil directly applicationor via plant root exudates. This input of pesticides can affect many soil organisms in different manners. Some soil bacteria can tolerate certain pesticides and possibly core use as carbon or nitrogensource [5] [6]. Bacteriostatic and lethal effects of pesticides can also occur [7].

Rhizobia are known for their ability to form $\mathrm{N}_{2}$-fixing nodules in symbiosis with legumes. The adverse effect on rhizobia negatively affects the legume Rhizobium symbiosis and consequently reduces the rate of biological nitrogen fixation. Previous studies reported various effects of the different classes of pesticides (insecticides, herbicides and fungicides) on rhizobia. Some pesticides were reported to inhibit rhizobial growth [8]-[11]. Therefore effect of pesticides on legume rhizobia symbiosis, will vary according to the rhizobial species strains, [12] [13] the rhizobial strains within a given species [10] [14]-[16] the type of pesticide involved [12] [14] [15] [17] and/or to the pesticide concentration [18]. Reported studies regarding pesticides effects on free living or symbiotic rhizobia are usually scattered and done with few pesticides on a limited number of strains [11] [18]-[20] or with a limited number of pesticides on different strains of the same genus [10] [17] [21]. The aim of the present study is to assess the performance of two rhizobials trains belonging to clover and peanut species in relation to Vitavax and Rizolex fungicides persistance.

\section{Materials and Methods}

\subsection{Fungicides}

Vitavax is asingle compound containg to aromtic ringes with a chemical formula of: 5, 6-dihydro-2-methyl-1, 4oxathiin-3-carboxanilide.

Whereas Rizolex is blend of Thiram and Tolcofs methyl fungicides in 1:1 ratio with a chemical formula: dimethylcarbamothioylsulfanyl N, N-dimethylcarbamoditt.

The performance of for the fungicides strains degradation was tested using the colorimetric assay and the HPLC analysis of degradation products:

\subsection{A-Determination of Vit Residues Using HPLC}

Sample extraction: At the end of the experiment (240 hours), the growth of rhizobialbio mass (TA1) in liquid media amended with $2000 \mathrm{ppm}$ Vit was removed by centrifugation. Five ml of the supernatant was extracted three times with dichloro methane. The dichloro methane was evaporated to dryness under stream of nitrogen. The residue was dissolved in $1 \mathrm{ml}$ acetonitrile (Mobil phase) and $5 \mu \mathrm{l}$ were injected in HPLC HP1100 with mobile phase acetonitrile, water $65 \%$ and $35 \%$ respectively. The HPLC is Equipped with quaternary gradient pump with flow rate $1 \mathrm{ml} / \mathrm{min}$., thermostatic controlled reversed phase C18 column (200 mm $\times 4.5 \mathrm{~mm} \times 5 \mu \mathrm{m})$ and $\mathrm{UV}$-Vis detector at $254 \mathrm{~nm}$. The concentratins of the compounds were determined based on the peak area.

\subsection{Determination of Riz Residues Using Colorimetric Analysis}

Preparation of Riz standard curve: Thiram is the main active ingredient in Riz fungicide. An exact weight of Riz (33.3 mg, $26.64 \mathrm{mg}, 19.28 \mathrm{mg}, 13.32 \mathrm{mg}$ and 6.66mg) were dissolved in $10 \mathrm{ml}$ distilled water to prepare solutions containing Thiram concentration of 1000, 800, 600, 400 and $200 \mathrm{ppm}$. Aliquots of $400 \mu \mathrm{l}$ were taken from each solution and extracted three times by chloroform. The chloroform was evaporated to dryness. The residues were dissolved in $2.5 \mathrm{ml}$ distilled water, $1 \mathrm{ml} \mathrm{CuSO}_{4} 0.5 \%$, and $1 \mathrm{ml} \mathrm{H}_{2} \mathrm{SO}_{4}$. The absorbance was measured using spectrophotometer against reagent blank at $420 \mathrm{~nm}$.

Colorimetric assay of Riz residues in cultural media: Two flasks were used to determine Thiram at zero time, 48, 72, and $96 \mathrm{hrs}$. From each flask, $400 \mu \mathrm{l}$ were withdrawn and centrifuged to remove the cells. The clear supernatant was extracted three times by chloroform. The chloroform was evaporated to dryness. The Thriam residues were dissolved in solutions containing: $2.5 \mathrm{ml}$ distilled water, $1 \mathrm{ml} \mathrm{CuSO} \mathrm{C}_{4} 0.5 \%$, and $1 \mathrm{ml}_{2} \mathrm{SO}_{4}$ and the absorbance was measured using spectrophotometer at $420 \mathrm{~nm}$. 


\section{Results}

The performance of the strains for fungicides degradation was tested using the HPLC analysis and the colorimetric assay of degradation products. A local rhizobial isolate/strain from clover (TA1) and another one from peanut (8) proved to be resistant to the studied fungicides respectively Vitavax and Rizolex.

\subsection{Vitavax Biodegradation}

Clover strain $R$. legumesarm biover trifolii TA1 was grown on YEM broth media amended with 2000 ppm Vitavax fungicide. Control flasks without rhizobial inoculate were also included in the experiment for comparison. The degradation of fungicide by rhizobia was assessed by the HPLC-UV chromatography analyses. Four replicates of each treatment were included. Flasks were incubated in incubator shaker. Then the four similar flasks were polled together for HPLC sample assays at $150 \mathrm{rpm}$. The HPLC assays were preformed on culture samples from flasks after 48, 96, 144, 196 and 240 days of inculcation. The results of HPLC analyses of control sample showed specific peak indicating the Vitavax presence in the medium (Figure 1). This specific peak was found in all samples from the control at different time intervals. In Vitavax treated flasks inoculated with clover rhizobial strain, the specific peak of the Vitavax fungicide started to reduce as the incubation time goes on (Figures 2(a)-(e)). Two new peaks were observed in the media containing Vitavax and Rhizobium. The area of these two peaks generally increased with the increase in incubation time. The data clearly show that Vitavax fungicide did not degrade completely until the end of the experiment after 240 hours of incubation. However two new intermediates were released into the medium indicating rhizobial degradation of the fungicide.

Table 1 shows that the peak area of Vitavax active ingredient (carboxine chemical) decreased gradually till the end of inculcation period (240 hours), where the residual Vitavax was $23.8 \%$ of the original concentration of Vitavax. It is also clear from Figure 3 that close to $76 \%$ of the fungicide was degraded in 240 hours. Table 1 also shows that the fungicide degradation was sharp in early incubation with rhizobia strain. The calculation of concentration of the fungicide was based on corresponding peak area as compared to the original known concentration of Vitvax.

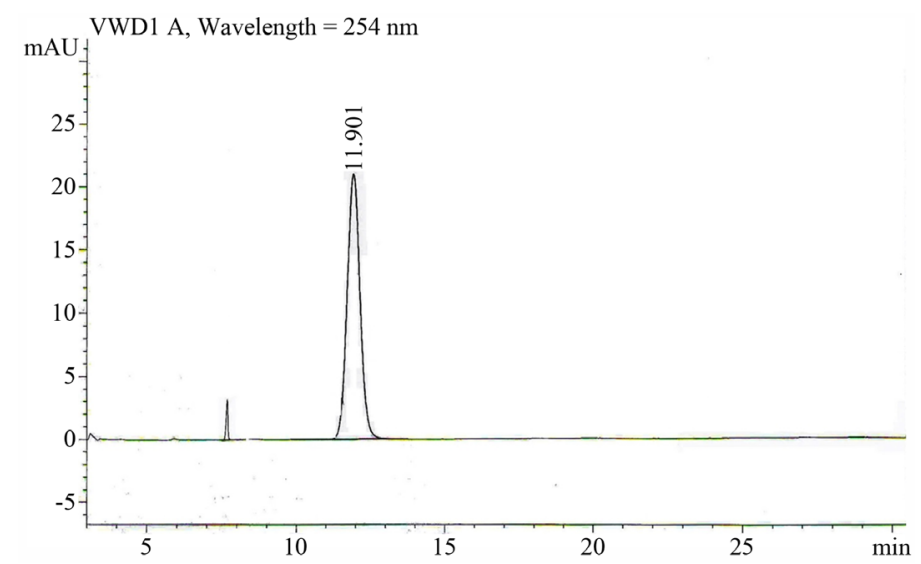

Figure 1. HPLC chromatogram of YEM broth medium amended with 2000 ppm Vitavax fungicide (Control).

Table 1. Vitavax degradation by Rhizobium legume biover trifolii strain TA1.

\begin{tabular}{ccc}
\hline Incubation (hours) & HPLC peak area & Changes in Vitavax concentration (ppm) \\
\hline $\mathbf{0}$ & 566 & 2000.00 \\
$\mathbf{4 8}$ & 364 & 1286.20 \\
$\mathbf{9 6}$ & 229.23 & 810.306 \\
$\mathbf{1 4 4}$ & 198.46 & 701.601 \\
$\mathbf{1 9 6}$ & 170.79 & 603.81 \\
$\mathbf{2 4 0}$ & 134.36 & 475.00 \\
\hline
\end{tabular}




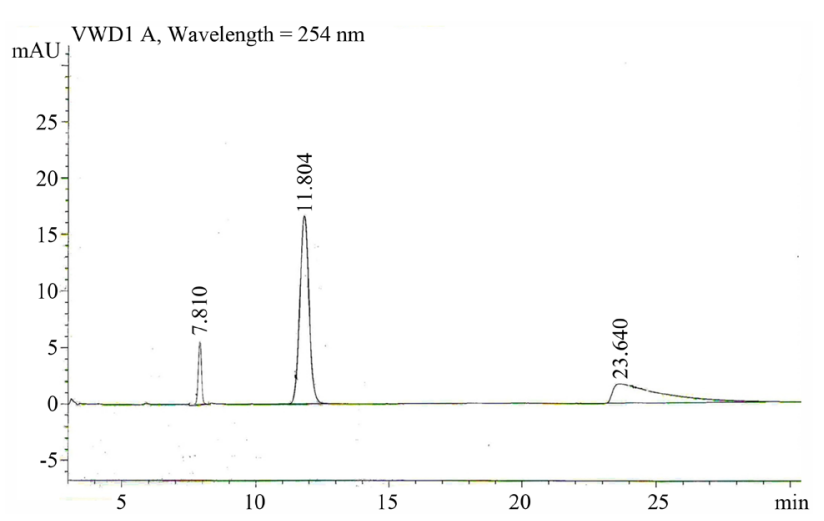

(a)

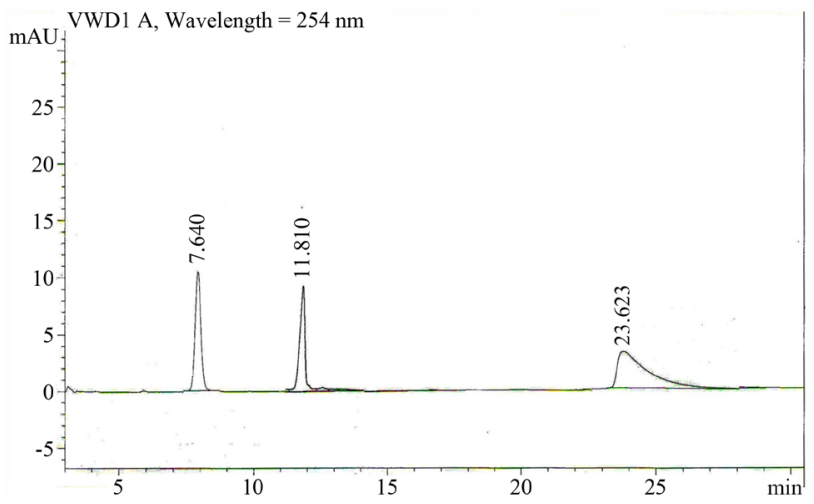

(b)

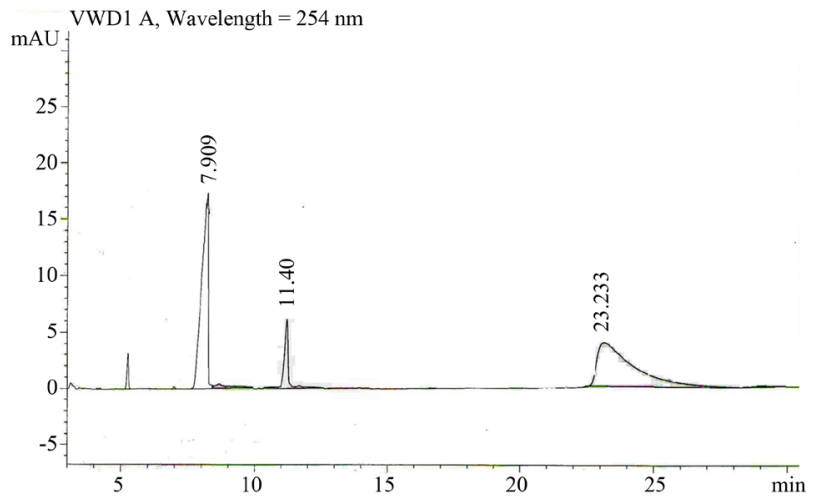

(c)

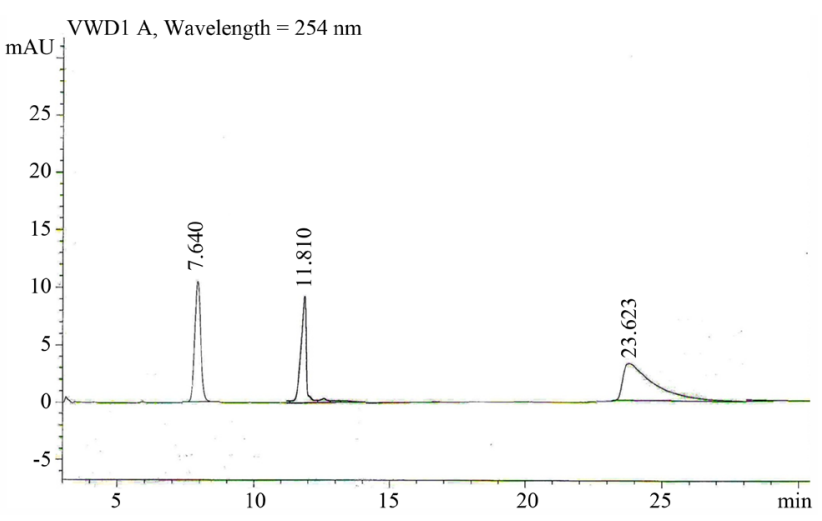

(d) 


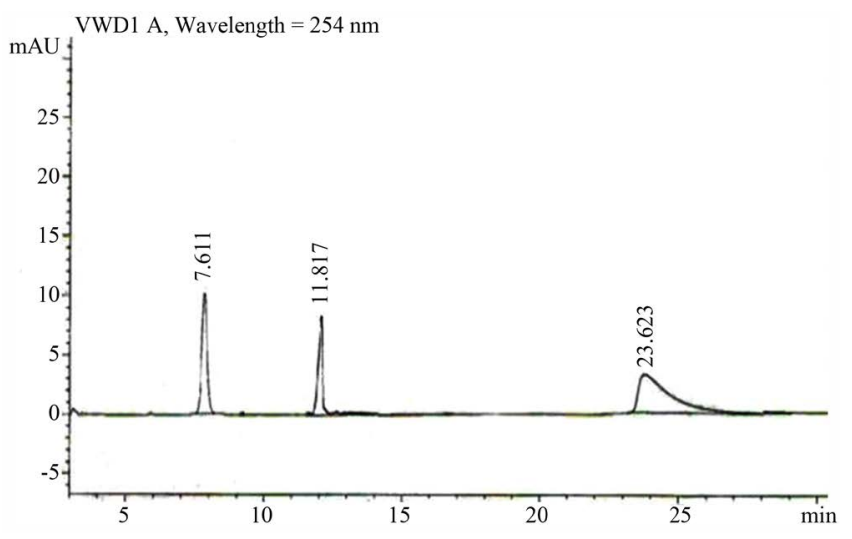

(e)

Figure 2. Chromatogram showing degradation of Vitavax by clover rhizobial strain TA1. HPLC-UV chromatograms analysis using C18 column. (a)-(e) show the degradation after 48, 96, 144, 196 and 240 hours of incubation.

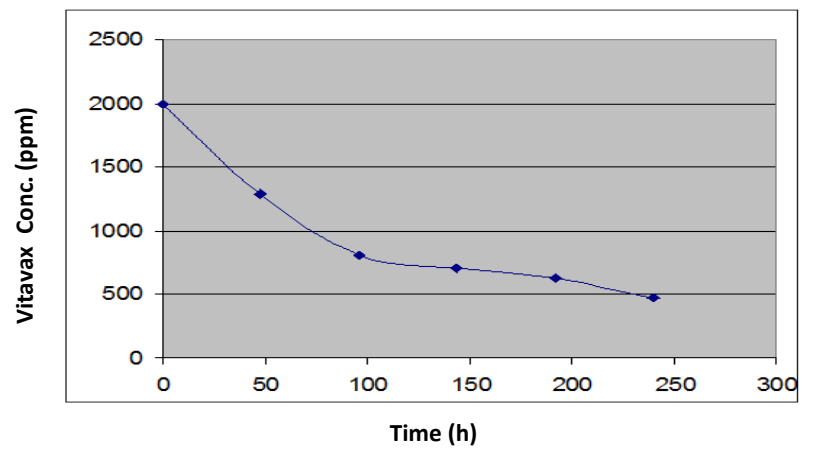

Figure 3. Biodegradation of Vitavax fungicide by rhizobial clover strain TA1.

\subsection{Rizolex Biodegradation}

The biodegradation of Rizolex fungicide by peanut rhizobial isolate 8 that showed high resistance to the studied fungicide. The fungicide biodegradation was assessed by measuring the Thiram fungicide. The rate of Thiram active ingredient degradation was studied by colorimetric assay in the broth media in $250 \mathrm{ml}$ glass flasks. The media was amended with $2000 \mathrm{ppm}$ commercial fungicide, which contains $1000 \mathrm{ppm}$ Thiram active ingredient. The flasks were incubated at $28^{\circ} \mathrm{C}$. Two flasks were removed every 48 hours to determine the remaining Thiram. The results show that $45 \%$ of the Thiram was degraded sharply during the first $40 \mathrm{~h}$. The concentrations of Thiram were further dropped in the medium from $1000 \mathrm{ppm}$ to $150 \mathrm{ppm}$ after another 48 hours then the final concentration of Thiram was reduced to $10 \mathrm{ppm}$ after 144 hours of incubation. After 196 hours of inculcation no Thiram disappeared totally from the medium. The results clearly show that the peanut rhizobial isolate No. 8 was capable to degrade the main component of Rizolex fungicide (Thiram), as the concentration of this compound decreased from 1000ppm in the medium to zero ppm (Figure 4 and Table 2).

\section{Discussion}

The resistance of certain rhizobial strains or isolates to high concentrations of the two fungicides could be due to the capacity of the rhizobia to protect their cells from the toxic effect of the fungicides or to the ability of rhizobia to degrade these chemicals as a mechanism to avoid its toxic effects. In the present study the most resistant clover and peanut rhizobial strains were exposed to $2000 \mathrm{ppm}$ concentrations of each of the two fungicides, then the residues of fungicides were measured in the media using HPLC for Vitavax residue determination and calorimetrically for Rizolex residues measurement. Clear degradation of Vit fungicide by Rhizobium leguminosarum 


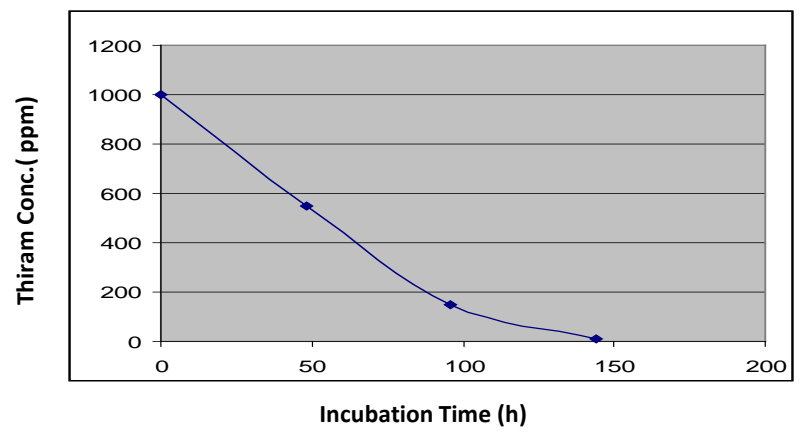

Figure 4. Changes in Thiram concentration with time in broth medium inoculated with peanut rhizobial isolate 8 .

Table 2. Rhizobial biodegradation of Thiram in broth media.

\begin{tabular}{ccc}
\hline Incubation hours & Optical intensity at $\mathbf{5 5 0}$ wavelength & Changes in Thiram concentration (ppm) \\
\hline $\mathbf{0}$ & 0.83 & 1000 \\
$\mathbf{4 8}$ & 0.49 & 550 \\
$\mathbf{9 6}$ & 0.12 & 150 \\
$\mathbf{1 4 4}$ & 0.01 & 10 \\
$\mathbf{1 9 6}$ & 0.00 & 0 \\
\hline
\end{tabular}

biovar trifolii strain TA1 was evident. New intermediates were formed in the medium these intermediates increased with incubation time; however, the Vit fungicide was not completely degraded in 10 days of incubation (only $75 \%$ were degraded). Similar results were obtained by [22].

Regarding the degradation of Riz fungicide by Bradyrhizobium sp. isolate 8, the present study showed that about $45 \%$ of fungicide was degraded in 48 hours of incubation. The degradation was increased with time and the Thiram (active ingredient of Riz fungicide) disappeared totally after 196 hours. This indicates that the peanut rhizobial isolate 8 was able to degrade the fungicide in the growth medium this is in agreement with results ofRamos and Ribeiro [23] who study the treated seeds with rhizobia and inoculation with Benlate, Vitavax, Banrot, Difolatan or Ridomil fungicides. This rhizobial strains are used showed greater survival on the seed with fungicide.

The effect of both fungicides on rhizobial inoculants performance was addressed in this study. Negative effects on rhizobial inoculants performance were recorded. This negative effect differed from one crops to another. Vitavax fungicide application with clover rhizobial inoculants significantly reduced plant dry weight, nodule number as well as plant nitrogen content. Same effect was also noted with the application of Rizolex fungicide to clover. This may be due to the effect of these toxic chemicals on survival of the rhizobia in the soil and rhizosphere of the legume. The same results are stated by Kari [24] who found that the Captan and Thiram significantly reduced the numbers of rhizobia recovered from legume seed.

\section{Conclusion}

This work shows that fungicides had the highest deleterious effects on the rhizobia. The two fungicides that affected the higher number of strains were Vitavaxand Rizolex. We identified two rhizobial isolates that were not affected by any of the fungicides tested at any concentration (clover rhizobia isolate TA1 and peanut isolate 8).

\section{References}

[1] Kauffman, A.K. (1987) Applied Bioremedial Technology. Applied Biotreatment Association, Washington DC, 423426.

[2] Racke, K.D. and Coats, J.L. (1990) Enhanced Biodegradation of Pesticides in the Environment. American Chemical Society Symposium Series, 426. 
[3] Shirkot, C.K. and Gupta, K.G. (1985) Accelerated Tetramethylthiuram disulfide (TMTD) Degradation in Soil by Inoculation with TMTD-Utilizing Bacteria. Bulletin of Environmental Contamination and Toxicology, 35, 354-361. http://dx.doi.org/10.1007/BF01636522

[4] Shirkot, C.K., Shirkot, P., Dhall, S.P. and Gupta, K.G. (1990) Effectiveness of Pseudomonas aeruginosafor Detoxificaton of Tetramethylthiuramdisufide (TMTD) from Contaminated Soil. Bulletin of Environmental Contamination and Toxicology, 44, 317-324. http://dx.doi.org/10.1007/BF01700153

[5] Dick, R.E. and Quinn, J.P. (2006) Glyphosate-Degrading Isolates from Environmental Samples: Occurence and Pathways of Degradation. Applied Microbiology and Biotechnology, 43, 545-550. http://dx.doi.org/10.1007/BF00218464

[6] Sarnaik, S.S., Kanekar, P.P., Raut, V.M., Taware, S.P., Chavan, K.S. and Bhadbhade, B.J. (2006) Effect of Application of Different Pesticides to Soybean on the Soil Microflora. Journal of Environmental Biology, 27, 423-426.

[7] Fox, J.E., Gulledge, J., Engelhaupt, E., Burrow, M.E. and McLachlan, J.A. (2007) Pesticides Reduce Symbiotic Efficiency of Nitrogen-Fixing Rhizobia and Host Plants. Proceedings of the National Academy of Sciences of the United States of America, 104, 10282-10287. http://dx.doi.org/10.1073/pnas.0611710104

[8] Gonzalez, A., González-Murua, C. and Royuela, M. (1996) Influence of Imazethapyr on Rhizobium Growth and Its Symbiosis with Pea (Pisumsativum). Weed Research, 44, 31-37.

[9] Singh, G. and Wright, D. (2002) In Vitro Studies on the Effects of Herbicides on the Growth of Rhizobia. Letters in Applied Microbiology, 35, 12-16. http://dx.doi.org/10.1046/j.1472-765X.2002.01117.X

[10] dos Santos, J.B., Ferreira, E.A., Kasuya, M.C.M., da Silva, A.A. and Procópio, S.O. (2005) Tolerance of Bradyrhizobiumstrains to Glyphosate Formulations. Crop Protection,' 24, 543-547. http://dx.doi.org/10.1016/j.cropro.2004.10.007

[11] Khan, H., Zeb, A., Ali, Z. and Shah, S.M. (2009) Impact of Five Insecticides on Chickpea (CicerarietinumL.) Nodulation, Yield and Nitrogen Fixing Rhizospheric Bacteria. Soil and Environment, 28, 56-59.

[12] Zahran, H.H. (1999) Rhizobium-Legume Symbiosis and Nitrogen Fixation under Severe Conditions and in an Arid Climate. Microbiology and Molecular Biology Reviews, 63, 968-989.

[13] Shafiani, S. and Malik, A. (2003) Tolerance of Pesticides and Antibiotic Resistance in Bacteria Isolated from Wastewater-Irrigated Soil. World Journal of Microbiology \& Biotechnology, 19, 897-901. http://dx.doi.org/10.1023/B:WIBI.0000007290.94694.4f

[14] Tu, C.M. (1980) Effect of Fungicides on Growth of Rhizobium japonicumin Vitro. Bulletin of Environmental Contamination and Toxicology, 25, 364-368. http://dx.doi.org/10.1007/BF01985539

[15] Moorman, T.B. (1986) Effects of Herbicides on the Survival of Rhizobium japonicum Strains. Weed Science, 34, 628633.

[16] Zablotowicz, R.M. and Reddy, K.N. (2004) Impact of Glyphosate on the Bradyrhizobiumjaponicum Symbiosis with Glyphosate-Resistant Transgenic Soybean: A Mini Review. Journal of Environmental Quality, 33, 825-831. http://dx.doi.org/10.2134/jeq2004.0825

[17] Kaur, C., Maini, P. and Shukla, N.P. (2007) Effect of Captan and Carbendazim Fungicides on Nodulation and Biological Nitrogen Fixation in Soybean. Asian Journal of Experimental Sciences, 21, 385-388.

[18] Zawoznik, M.S. and Tomaro, M.L. (2005) Effect of Chlorimuron-Ethyl on Bradyrhizobiumjaponicum and its Symbiosis with Soybean. Pest Management Science, 61, 1003-1008.

[19] Cardina, J., Hartwig, N.L. and Lukezic, F.L. (1986) Herbicidal Effects on Growth of Rhizobia and Nodule Activity. Weed Science, 34, 338-343.

[20] Srinivas, T., Sridevi, M. and Mallaiah, K.V. (2008) Effect of Pesticides on Rhizobium and Nodulation of Green Gram Vigna radita (L.) Wilczek. The IUP Journal of Life Sciences, 2, 36-44.

[21] Tesfai, K. and Mallik, M.A.B. (1986) Effect of Fungicide Application on Soybean-Rhizobia Symbiosis and Isolation of Fungicide-Resistant Strains of Rhizobium japonicum. Bulletin of Environmental Contamination and Toxicology, 36, 819-826. http://dx.doi.org/10.1007/BF01623589

[22] Erin, M.B. and Knight, J.D. (2005) Survival of Penicillium bilaiae Inoculated on Canola Seed Treated with Vitavax RS and Extender. Biology and Fertility of Soils, 42, 54-59. http://dx.doi.org/10.1007/s00374-005-0862-7

[23] Ramos, M.L.G. and Ribeiro, W.Q. (1993) Effect of Fungicides on Survival of Rhizobium on Seeds and the Nodulation of Bean (Phaseolus vulgaris L.). Plant and Soil, 152, 145-150. http://dx.doi.org/10.1007/BF00016344

[24] Dunfield, K.E., Siciliano, S.D. and Germida, J.J. (2000) The Fungicides Thiram and Captan Affect the Phenotypic Characteristics of Rhizobium leguminosarum Strain C1 as Determined by FAME and Biolog Analyses. Biology and Fertility of Soils, 31, 303-309. http://dx.doi.org/10.1007/s003740050660 